\title{
Direct oral anticoagulants in patients with
} nonvalvular atrial fibrillation: a real-world experience from a single Spanish regional hospital.

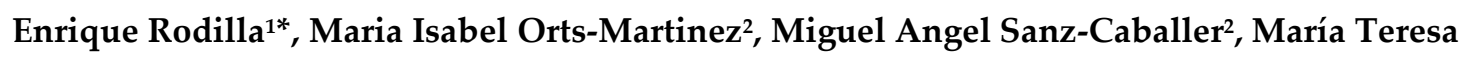 \\ Gimeno-Brosel $^{2}$, Maria Jesús Arilla-Morel ${ }^{2}$, Isabel Navarro-Gonzalo², Inmaculada \\ Castillo-Valero ${ }^{2}$, Inmaculada Salvador-Mercader ${ }^{3}$, Ana Carral-Tatay ${ }^{2}$. \\ 1 Internal Medicine, University Hospital of Sagunto, Universidad Cardenal Herrera-CEU, CEU Universities, Valencia, \\ Spain; enrique.rodilla@uchceu.es (ER) \\ 2 Hematology, University Hospital of Sagunto, Valencia, Spain; ortsmaribel@hotmail.com (MIO); sanz_migcab@gva.es \\ (MAS); gimenomt@telefonica.net (MTG); arilla_mja@gva.es (MJA); navarro_isa@gva.es (ING); \\ icastillovalero@hotmail.es (ICV); \\ 3 Cardiology, University Hospital of Sagunto, Valencia, Spain; insamer@hotmail.com (ISM); \\ 4 Hematology, University Hospital of Sagunto, Valencia, Spain; carral ana@gva.es (ACT). \\ * Correspondence: enrique.rodilla@uchceu.es; Tel.: +34626488311
}

\begin{abstract}
The aim is to evaluate a program for direct oral anticoagulants (DOACs) management in nonvalvular atrial fibrillation (NVAF) patients, according to patient profiles, appropriateness of dosing, patterns of crossover, effectiveness and safety. This is an observational and longitudinal retrospective study in a cohort of patients attended in daily clinical practice in a single regional hospital in Spain with a systematic follow-up plan for up to 3 years for patients initiating dabigatran, rivaroxaban or apixaban between JAN/2012-DEC/2016. We analyzed 490 episodes of treatment (apixaban $2.5 \mathrm{mg}: 9.4 \%$, apixaban $5 \mathrm{mg}$ : $21.4 \%$, dabigatran $75 \mathrm{mg}: 0.6 \%$, dabigatran $110 \mathrm{mg}$ : $12,4 \%$, dabigatran $150 \mathrm{mg}: 19.8 \%$, rivaroxaban $15 \mathrm{mg}$ : $17.8 \%$ and rivaroxaban $20 \mathrm{mg}: 18.6 \%$ ) in 445 patients. $13.6 \%$ of patients on dabigatran, $9.7 \%$ on rivaroxaban, and $3.9 \%$ on apixaban, switched to other DOACs or changed dosing. Apixaban was the most frequent DOAC switched to. The most frequent reasons for switching were toxicity $(23.8 \%)$, bleeding $(21.4 \%)$ and renal deterioration (16.7\%). Inappropriateness of dose was found in $23.8 \%$ of episodes. Patients taking apixaban 2.5 $\mathrm{mg}$ were older, had higher CHA2DS2VASc score and lower creatinine clearance. Patients taking dabigatran $150 \mathrm{mg}$ and rivaroxaban $20 \mathrm{mg}$ were younger, had lower CHA2DS2VASc and higher creatinine clearance. Rates of stroke/transient ischemic attack (TIA) were 1.64/0.54 events/100 patients-years, while rates of major, clinically relevant non-major (CRNM) bleeding and intracranial bleeding where 2.4, 5, and 0.5 events $/ 100$ patients-years. Gastrointestinal and genitourinary bleeding were the most common type of bleeding events (BE). On multivariable analysis, prior stroke (RR: 4.2; CI: 1.5-11.8; $\mathrm{p}=0.006$ ) and age (RR: 1.2; CI: 1.1-1.4; $\mathrm{p}=0.006$ ) were independent predictors of stroke/TIA. Concurrent platelet inhibitors (RR: 7.1; CI: 2.3-21.8; $\mathrm{p}=0.001$ ), male gender (RR: 2.1; CI: 1.2-3.7; $\mathrm{p}=0.0012$ ) and age (RR: 1.1; CI: 1.02-1.13; $\mathrm{p}=0.005$ ) were independent predictors of BE. This study complements the scant data available on the use of DOACs in NVAF patients in Spain, confirming a good safety and effectiveness profile
\end{abstract}

Keywords: Direct oral anticoagulants (DOACs), Nonvalvular atrial fibrillation (NVAF); Real-world experience.

\section{Introduction}

Patients with non-valvular atrial fibrillation (NVAF) have an up to fivefold increased risk of stroke [1]. Vitamin K antagonists (VKA) have been for years the only anticoagulant treatment available. Recently, direct oral anticoagulants (DOACs) have entered the scene, demonstrating a better risk-benefit profile than VKA in randomized controlled trials (RCTs), reducing especially intracranial hemorrhage risk $[2,3,4]$. Post-marketing real-world observational studies on the effectiveness and safety of dabigatran [5,6], rivaroxaban [7] and apixaban [8] vs. warfarin, have shown general consistency with the respective RCTs. An important advantage of DOACs with 
respect to AVK is the predictable pharmacokinetics, with fewer drug and food interactions and no need for periodic laboratory monitoring. Thus, the current guidelines of the European Society of Cardiology recommend that DOACs should be preferred to VKAs in patients with NVAF who initiate anticoagulation $[9,10]$.

Despite its ease of use, DOACs remain high-risk medications that must be handled carefully to avoid bleeding and thrombotic complications. To maximize safety and efficacy, appropriate initial DOAC and dose selection, and over time dose adjustments, must take into consideration patients characteristics such as age, renal function, weight, comorbidity and concomitant medications. In addition, careful handling of invasive procedures and surgery should be done, as well as appropriate management of bleeding events. Hence, for proper handling of these drugs, training of physicians attending anticoagulated patients, as well as patient education is essential.

Nevertheless, the usage rates of DOACs in Spain have been lower than in neighboring countries, mainly because of administrative restrictions limiting the indications of DOACs to situations of poor INR control, ineffectiveness of VKA, contraindications to VKA, increased risk of intracranial hemorrhage or inability to access INR facilities. Furthermore, studies evaluating effectiveness and safety of DOAC in the Spanish population are very scarce $[11,12,13]$. The lack of information about real world practice with DOACs in Spain represents a burden that prevents many patients from getting an adequate treatment of NVAF.

We therefore designed in the Hematology Service of Sagunto Hospital (Valencia, Spain) a management program for patients with NVAF initiating DOACs in our health area. Our goal was to evaluate the effectiveness and safety of DOACs in patients diagnosed of NVAF from 2012 on, reporting the results of our program.

\section{Subjects and Methods}

Our hospital is a regional hospital that provides care for over 150,000 people and manages over 3,500 patients anticoagulated with VKA. In 2012 we designed a management plan for prescription of patients DOACs in patients with NVAF, that included the following aspects:

- We developed a DOACs guide, covering the most important aspects of treatment.

- Educational seminars were given at the hospital and in Primary Care Centers.

- The anticoagulation management database (Gota, Werfen) was regularly tracked to locate those patients susceptible to DOACs for meeting any of the criteria established by the health authorities of our country.

- Cardiologists, Internists and General Practitioners of our health area participated in a protocol for referral to the Hematology Unit of all patients starting DOACs.

- On the first clinical appointment, at the start of therapy, patients received verbal and printed information from a trained nurse.

- A systematic follow-up plan of patients was established, including clinical and analytical data (see below). Patients were discharged at three years, with specific follow-up recommendations for Primary Care doctors.

Concerning design, study population and study period, this was a longitudinal, retrospective observational study carried out in the framework of the DOACs management program described above.

All patients with NVAF attending the Hematology Service of Hospital Sagunto who started treatment with apixaban, rivaroxaban or dabigatran between April, 1st of 2012 and December, 31st of 2016 were included. Edoxaban was not included in the analysis too few patients were on treatment due to its late date of marketing. The final analysis was performed on December, 31st of 2017, after having completed one year of follow-up for the last patient included. The choice of DOAC and dose was made by the first prescribing physician according to his criteria within the framework of the DOACs guide of our health area.

According to the management protocol, patients underwent clinical and analytic evaluation at baseline, at 3 months, one year, two years and three years after initiating DOACs. For each patient, the following data were obtained at baseline: date of birth, gender, weight, clinical data (HTA, DM, 
prior stroke/transient ischemic attack (TIA), prior bleeding events, vascular disease: acute myocardial infarction (AMI) or peripheral arteriopathy, alcohol abuse), analytic data (hemoglobin, creatinine, liver enzymes), treatment with platelet aggregation inhibitors. CHA2DS2VASc and HAS-BLED scores and creatinine clearance (Cockcroft-Gault formula) were calculated.

On follow-up, analytic data (hemoglobin, creatinine, liver enzymes), adverse reactions, thromboembolic events and bleeding events were collected. Data were recorded in a case report form, and in a database (Microsoft Access 2007) specifically designed for the study.

Clinical effectiveness was assessed according to the presence or absence of episodes of ischemic stroke, TIA, or systemic thromboembolism (TE) and safety according to major and clinically relevant non-major (CRNM) bleeding (ISTH criteria) [14].

The confidentiality of records was respected. The study was classified by the Spanish Agency for Medicines and Heath Products (EPA-OD) and approved by the Research Ethics Committee of the Sagunto Hospital, Valencia. The study was conducted under conditions of routine clinical practice and no additional procedures or interventions were performed. All patients gave their informed consent at baseline.

All patients having completed at least the 3 months visit were included in the analysis, including the group of subjects in which the DOAC was suspended because of toxicity, bleeding, or TE. The statistical analyses were performed using the statistical software R, 3.5.2 [15]. For the descriptive analysis, qualitative variables were described as absolute frequencies and percentages, and quantitative variables were described as median and interquartile range. To assess whether there was a relationship between patients characteristics and DOAC administered, a bivariate analysis was performed. The association between categorical variables was evaluated using Fisher's exact test (with Monte Carlo p-value simulation for categorical variables with more than two categories). The Kruskal-Wallis test was used to compare quantitative variables, and when statistically significant, differences were detected, the Mann-Whitney test was used to determine between which treatment pairs there were such differences. In order to reduce the possibility of false positive inferences due to multiple comparisons between groups, the p-values were adjusted using the Benjamini \& Hochberg method [16]. Mann-Whitney and Kruskal-Wallis non-parametric tests were used as an alternative to the t-Student and ANOVA test when their conditions of applicability (normality and equal variable variances in each group) were not verified. The normality of the variables was tested using the Shapiro-Wilks test. Finally, in addition to calculating incidence rates of TE and bleeding events, Kaplan Meier curves were built. The comparison of these curves was performed using the log-rank test. Additionally, to find the subset of explanatory variables that provided a better fit of the model, a Cox regression analysis was performed, applying the automatic procedure of backward selection of variables in addition to the Akaike Information Criterion (AIC). The time to the first event was used to construct Kaplan-Meier curves and for Cox regression analysis, whereas all events that occurred were included to calculate event rate. The limit of significance was set at 0.05 .

\section{Results}

\subsection{Demographic characteristics of the study population}

Baseline patient characteristics are shown in Table 1. Median age was 76 years (Q1-Q3: 70-80), $53 \%$ of patients were male, median creatinine clearance was $68 \mathrm{ml} / \mathrm{min}$ (Q1-Q3: 53.8-88), median CHA2DS2VASc score was 4 (Q1-Q3: 3-5), median HAS-BLED score was 1 (Q1-Q3: 1-2), 27.6\% of patients had had a prior TE and 6 patients $(1.2 \%)$ were taking platelet aggregation inhibitors. Overall, median follow-up was 24 months (Q1-Q3: 12-36), it was similar among all treatment 
Table 1: Baseline patients' characteristics by study group

\begin{tabular}{|c|c|c|c|c|c|c|c|c|c|}
\hline Study groups & $\begin{array}{c}\text { Apixaban } \\
2.5 \mathrm{mg}\end{array}$ & $\begin{array}{c}\text { Apixaban } \\
5 \mathrm{mg}\end{array}$ & $\begin{array}{c}\text { Dabigatran } \\
110 \mathrm{mg}\end{array}$ & $\begin{array}{c}\text { Dabigatran } \\
150 \mathrm{mg}\end{array}$ & $\begin{array}{c}\text { Rivaroxaban } \\
15 \mathrm{mg}\end{array}$ & $\begin{array}{c}\text { Rivaroxaban } \\
20 \mathrm{mg}\end{array}$ & $\begin{array}{c}\text { Dabigatrán } \\
75 \mathrm{mg}\end{array}$ & total & \\
\hline Number of episodes & $\begin{array}{l}n=46 \\
(9.4 \%)\end{array}$ & $\begin{array}{l}n=105 \\
(21.4 \%)\end{array}$ & $\begin{array}{c}n=61 \\
(12.4 \%)\end{array}$ & $\begin{array}{c}n=97 \\
(19.8 \%)\end{array}$ & $\begin{array}{c}n=87 \\
(17.8 \%)\end{array}$ & $\begin{array}{c}n=91 \\
(18.6 \%)\end{array}$ & $\begin{array}{c}n=3 \\
(0.6 \%)\end{array}$ & $\begin{array}{l}n=490 \\
(100 \%)\end{array}$ & \\
\hline $\begin{array}{l}\text { Follow-up (months) } \\
\text { median } \\
\text { interquartile range }\end{array}$ & $\begin{array}{c}21.6 \\
(12-3.4)\end{array}$ & $\begin{array}{c}24 \\
(12-36)\end{array}$ & $\begin{array}{c}24 \\
(12-36)\end{array}$ & $\begin{array}{c}24 \\
(12-36)\end{array}$ & $\begin{array}{c}24 \\
(12-36)\end{array}$ & $\begin{array}{c}24 \\
(12-36)\end{array}$ & $\begin{array}{c}7.7 \\
(6.8-21.8)\end{array}$ & $\begin{array}{c}24 \\
(12-36)\end{array}$ & NS \\
\hline $\begin{array}{l}\text { Age }-\mathrm{yr} \\
\text { median } \\
\text { interquartile range }\end{array}$ & $\begin{array}{c}83 \\
(80-86) \\
\end{array}$ & $\begin{array}{c}74 \\
(69-78) \\
\end{array}$ & $\begin{array}{c}80 \\
(78-82) \\
\end{array}$ & $\begin{array}{c}71 \\
(64-76) \\
\end{array}$ & $\begin{array}{c}79 \\
(77-82) \\
\end{array}$ & $\begin{array}{c}71 \\
(66-75)\end{array}$ & $\begin{array}{c}79 \\
(78.5-81.5) \\
\end{array}$ & $\begin{array}{c}76 \\
(70-80) \\
\end{array}$ & $<0.001^{\mathrm{a}}$ \\
\hline Female sex - no. (\%) & $27(58.7 \%)$ & $47(44.8 \%)$ & $34(55.7 \%)$ & $37(38.1 \%)$ & $45(51.7 \%)$ & $36(39.6 \%)$ & $3(100 \%)$ & $229(46.7 \%)$ & NS \\
\hline $\begin{array}{c}\text { creatinine clearance }-\mathrm{ml} / \mathrm{min} \\
\text { median } \\
\text { interquartile range }\end{array}$ & $\begin{array}{c}42 \\
(33.3-52)\end{array}$ & $\begin{array}{c}68 \\
(55-88)\end{array}$ & $\begin{array}{c}65 \\
(52-77)\end{array}$ & $\begin{array}{c}83.5 \\
(71-102.3)\end{array}$ & $\begin{array}{c}58 \\
(45-70)\end{array}$ & $\begin{array}{c}79 \\
(61-107.5) \\
\end{array}$ & $\begin{array}{c}47 \\
(41-55.5) \\
\end{array}$ & $\begin{array}{c}68 \\
(53.8-88)\end{array}$ & $<0.001^{b}$ \\
\hline $\begin{array}{l}\text { CHADsVASc } \\
\text { median } \\
\text { interquartile range }\end{array}$ & $\begin{array}{c}5.5 \\
(4-6)\end{array}$ & $\begin{array}{c}4 \\
(3-5)\end{array}$ & $\begin{array}{c}5 \\
(4-6)\end{array}$ & $\begin{array}{c}3 \\
(2-5)\end{array}$ & $\begin{array}{c}5 \\
(4-6)\end{array}$ & $\begin{array}{c}3 \\
(2-4)\end{array}$ & $\begin{array}{c}5 \\
(4.5-6)\end{array}$ & $\begin{array}{c}4 \\
(3-5)\end{array}$ & $<0.001^{\mathrm{c}}$ \\
\hline $\begin{array}{l}\text { Prior stroke, TIA, or systemic embolism - } \\
\text { no. (\%) }\end{array}$ & $21(45.7 \%)$ & $18(17.1 \%)$ & $21(34.4 \%)$ & $29(29.9 \%)$ & $28(32.2 \%)$ & $17(18.7 \%)$ & $1(33.3 \%)$ & $\begin{array}{c}135 \\
(27.6 \%)\end{array}$ & $<0.001^{d}$ \\
\hline $\begin{array}{l}\text { HAS-BLED } \\
\text { median } \\
\text { interquartile range }\end{array}$ & $\begin{array}{c}2 \\
(1-2) \\
\end{array}$ & $\begin{array}{c}1 \\
(1-2) \\
\end{array}$ & $\begin{array}{c}1 \\
(1-2) \\
\end{array}$ & $\begin{array}{c}1 \\
(1-2) \\
\end{array}$ & $\begin{array}{c}1 \\
(1-2)\end{array}$ & $\begin{array}{c}1 \\
(1-1)\end{array}$ & $\begin{array}{c}1 \\
(1-2)\end{array}$ & $\begin{array}{c}1 \\
(1-2)\end{array}$ & $<0.001^{\mathrm{e}}$ \\
\hline antiplatelet drugs - no. (\%) & $0(0 \%)$ & $1(0.95 \%)$ & $1(1.6 \%)$ & $0(0 \%)$ & $4(4.6 \%)$ & $0(0 \%)$ & $0(0 \%)$ & $6(1.2 \%)$ & NS \\
\hline
\end{tabular}

a. Age: there were significant differences in all comparisons, except D150 versus R20 and D110 versus R15. Patients receiving A2.5 were significantly older than all other groups and those receiving D150 and R20 significantly younger than all other groups (Ax2,5 > D110 y R15 > Ax5 > D150 y R20).

b. Creatinine clearance: there were significant differences in all comparisons, except D150 versus R20, D110 versus R15, D110 versus A5 and A2.5 versus R15. Patients who received A2.5 had $\mathrm{CrCl}$ significantly lower than all other groups and those receiving D150 and R20 significantly higher than all other groups (Ax2,5 $<$ R15, D110, Ax5 $<$ D150 y R20).

c. $\mathrm{CHA}_{2} \mathrm{DS}_{2}$ VASc: significant differences in all comparisons, except A2.5 versus D110, A2.5 versus R15, D110 versus R15 and D150 versus R20. Patients who received A2.5 had a significantly higher score than all other patients (except those receiving D110 and R15) and those receiving D150 and R20 significantly lower than all other patients (A2,5 > D110 y R15 > A5 > D150 y R20). d Previous TE: significant differences between A2.5 - AP5 and A2.5 - R20

e HAS-BLED: significant differences between A2.5 versus A5, R20 and D150; between R15 versus R20 and D150; and between D110 versus R20 and D150 (A2,5 > D110 y R15 > A5 > D150 y R20 
groups. The distribution of DOACs was as follows: apixaban $2.5 \mathrm{mg} / 12 \mathrm{~h}$ in 46 episodes $(9.4 \%)$, apixaban $5 \mathrm{mg} / 12 \mathrm{~h}$ in 105 (21.4\%), dabigatran $75 \mathrm{mg} / 12 \mathrm{~h}$ in $3(0.6 \%)$, dabigatran $110 \mathrm{mg} / 12 \mathrm{~h}$ in 61 $(12.4 \%)$, dabigatran $150 \mathrm{mg} / 12 \mathrm{~h}$ in $97(9.8 \%)$, rivaroxaban $15 \mathrm{mg} / \mathrm{d}$ in $87(17.8 \%)$ and rivaroxaban 20 $\mathrm{mg} / \mathrm{d}$ in $91(18.6 \%)$. In the whole cohort the standard dose was prescribed in $60 \%$ of episodes and the lower presentation in $40 \%$.

Table 1 also shows significant differences among the treatment groups concerning age, creatinine clearance, CHA2DS2VASc, HAS-BLED and previous TE. Patients taking apixaban $2.5 \mathrm{mg}$ where older, had higher CHA2DS2VASc score and lower creatinine clearance. Patients taking dabigatran $150 \mathrm{mg}$ and rivaroxaban $20 \mathrm{mg}$ where younger, had lower CHA2DS2VASc and higher creatinine clearance, while subjects on apixaban 2.5 had significantly higher percentage of prior TE than patients on apixaban $5 \mathrm{mg}$ or rivaroxaban $20 \mathrm{mg}$.

In 445 patients initiating ACOD, 387 (86.9\%) were previously receiving VKA and 58 (13.1\%) started anticoagulation "de novo". The most frequent reasons for substituting AVK for DOAC were the following: poor INR control in 308 patients $(79.5 \%)$ and TE in 42 patients (10.8\%) (Table 2).

Table 2: Previous use of VKA and reasons for switching from VKA to DOAC

\begin{tabular}{llc}
\hline No & 58 patients (13.1\%) & \\
\hline Yes & 387 patients (86.9\%) & \\
& Reasons for switching to DOAC: & $308(79.5 \%)$ \\
& Poor INR control with good VKA compliance & $42(10.8 \%)$ \\
Thromboembolic complication & $12(3.1 \%)$ \\
& Previous hemorrhagic stroke or high risk of intracranial bleeding & $7(1.8 \%)$ \\
Allergy or intolerance to VKA & $5(1.3 \%)$ \\
Difficulties with follow-up & $13(3.3 \%)$ \\
Other &
\end{tabular}

Patients $\mathrm{n}=445$

In total, 490 episodes of treatment in 445 patients were analyzed. During the follow-up period 42 patients switched to a second DOAC, and of these, two patients switched to a third DOAC, and one of these patients was prescribed a fourth DOAC (Supplementary Table 1, Supplementary Figure 1). Dose adjustments and crossover between DOAC is shown in Supplementary Table 2, data from the first switch is shown. It occurred in $13.6 \%$ of patients prescribed dabigatran, $9.7 \%$ on rivaroxaban and $3.9 \%$ on apixaban ( $5.4 \%$ for the $5 \mathrm{mg}$ dose and no patient for the $2.5 \mathrm{mg}$ dose). Apixaban was the most frequent DOAC switched to, the $5 \mathrm{mg}$ dose in 12 cases (28.5\%) and de $2.5 \mathrm{mg}$ dose in 10 cases $(23.87 \%)$. In 19 patients $(45,2 \%)$ the initial dose (standard or lower) was maintained; in $16(38 \%)$ the dose was lowered and in $7(16.6 \%)$ increased. The most frequent reasons for switching were toxicity $(23.8 \%)$ (9 of 10 cases related to dabigatran dyspepsia), bleeding (21.4\%) and renal deterioration $(16.7 \%)$ (Table 3).

Table 3: Description of the reasons for switching between DOAC

\begin{tabular}{lc}
\hline Reasons for switching & Patients no. (\%) \\
\hline Toxicity* & $10(23.8 \%)$ \\
Hemorrhage & $9(21.4 \%)$ \\
Other & $9(21.4 \%)$ \\
Increased creatinine clearance & $7(16.7 \%)$ \\
Stroke & $4(9.5 \%)$ \\
Hemorrhage + increased creatinine clearance & $2(4.8 \%)$ \\
Iron-deficiency anemia without evident bleeding & $1(2.4 \%)$ \\
\hline
\end{tabular}

*9/10 cases of toxicity were related to dabigatran dyspepsia 
Table 4. Episodes with interrupted follow-up before study conclusion

\begin{tabular}{|c|c|c|c|c|c|c|c|c|}
\hline & $\begin{array}{c}\text { Apixaban } \\
2.5 \mathrm{mg} \\
(\mathrm{n}=46)\end{array}$ & $\begin{array}{c}\text { Apixaban } \\
5 \mathrm{mg} \\
(\mathrm{n}=105) \\
\end{array}$ & $\begin{array}{c}\text { Dabigatran } \\
110 \mathrm{mg} \\
(\mathrm{n}=61)\end{array}$ & $\begin{array}{c}\text { Dabigatran } \\
110 \mathrm{mg} \\
(\mathrm{n}=97)\end{array}$ & $\begin{array}{c}\text { Rivaroxaban } \\
15 \mathrm{mg} \\
(\mathrm{n}=87)\end{array}$ & $\begin{array}{c}\text { Rivaroxaban } \\
20 \mathrm{mg} \\
(\mathrm{n}=91)\end{array}$ & $\begin{array}{c}\text { Dabigatran } \\
75 \mathrm{mg} \\
(n=3)\end{array}$ & $\begin{array}{l}\text { Total } \\
(\mathrm{n}=490)\end{array}$ \\
\hline Total with interrupted follow-up (\%) & $17(37 \%)$ & $28(26.7 \%)$ & $25(41 \%)$ & $25(25.8 \%)$ & $35(40.2 \%)$ & $24(26.4 \%)$ & $2(66.7 \%)$ & $156(31.8 \%)$ \\
\hline \multicolumn{9}{|l|}{ Lost to follow up } \\
\hline no. (\%) & $1(2.2 \%)$ & $3(2.9 \%)$ & $1(1.6 \%)$ & $0(0 \%)$ & $1(1.2 \%)$ & $1(1.1 \%)$ & $0(0 \%)$ & $7(1.4 \%)$ \\
\hline months - median (Q1-Q3) & 12 & $13.2(10.3-3.8)$ & 11.8 & - & 3 & 4 & - & $11.8(5.7-12.6)$ \\
\hline $\begin{array}{l}\text { Death from stroke-hemorrhage }{ }^{a} \\
\text { no. }(\%)\end{array}$ & $0(0 \%)$ & $1(0.9 \%)$ & $1(1.6 \%)$ & $0(0 \%)$ & $2(2.3 \%)$ & $0(0 \%)$ & $0(0 \%)$ & $4(0.8 \%)$ \\
\hline months - median (Q1-Q3) & - & 35 & 10 & - & $15.5(13.7-17.4)$ & - & - & $15.5(11.4-23.1)$ \\
\hline \multicolumn{9}{|l|}{ Death from other causes } \\
\hline no. (\%) & $10(21.7 \%)$ & $7(6.7 \%)$ & $5(8.2 \%)$ & $2(2.1 \%)$ & $11(12.6 \%)$ & $3(3.3 \%)$ & $0(0 \%)$ & 38 (7.8\%) \\
\hline months - median (Q1-Q3) & $12.2(9.3-18)$ & $16.8(7.7-20.8)$ & $12.3(12.3-15.6)$ & $16.3(13.2-19.4)$ & $8.8(4.9-18.8)$ & $22.9(12-23.9)$ & - & $12.4(6-21.4)$ \\
\hline \multicolumn{9}{|l|}{ DOAC permanent Interruption } \\
\hline no. (\%) & $6(13 \%)$ & $17(16.2 \%)$ & $18(29.5 \%)$ & $23(23.7 \%)$ & $21(24.1 \%)$ & $20(22 \%)$ & $2(66.7 \%)$ & $107(21.8 \%)$ \\
\hline months - median (Q1-Q3) & $11(9-11.9)$ & $4.7(3.1-16.9)$ & $7.2(1.9-20)$ & $4.2(1.9-7.7)$ & $11.1(6.2-19.7)$ & $11.9(3.8-19.3)$ & $6.8(6.4-7.3)$ & $7.7(3.1-17.7)$ \\
\hline \multicolumn{9}{|l|}{ Reasons for interruption —no. (\%) } \\
\hline Bleeding & $1(2.2 \%)$ & $3(2.9 \%)$ & $2(3.3 \%)$ & $4(4.1 \%)$ & $3(3.4 \%)$ & $8(8.8 \%)$ & $0(0 \%)$ & 21 (4.3\%) \\
\hline Worsening $\mathrm{CrCl}$ & $0(0 \%)$ & $4(3.8 \%)$ & $1(1.6 \%)$ & $2(2.1 \%)$ & $4(4.6 \%)$ & $5(5.5 \%)$ & $0(0 \%)$ & $16(3.3 \%)$ \\
\hline Toxicity ${ }^{b}$ & $0(0 \%)$ & $1(0.9 \%)$ & $4(6.6 \%)$ & $7(7.2 \%)$ & $0(0 \%)$ & $0(0 \%)$ & $0(0 \%)$ & $12(2.4 \%)$ \\
\hline Stroke & $1(2.2 \%)$ & $2(1.9 \%)$ & $2(3.3 \%)$ & $1(1 \%)$ & $4(4.6 \%)$ & $0(0 \%)$ & $1(33.3 \%)$ & $11(2.2 \%)$ \\
\hline Anemia without overt & $0(0 \%)$ & $0(0 \%)$ & $1(1.6 \%)$ & $0(0 \%)$ & $2(2.3 \%)$ & $1(1.1 \%)$ & $0(0 \%)$ & $4(0.8 \%)$ \\
\hline Bleeding + worsening $\mathrm{CrCl}$ & $0(0 \%)$ & $1(0.9 \%)$ & $3(4.9 \%)$ & $0(0 \%)$ & $0(0 \%)$ & $0(0 \%)$ & $0(0 \%)$ & $4(0.8 \%)$ \\
\hline Other ${ }^{\mathrm{C}}$ & $4(8.7 \%)$ & $6(5.7 \%)$ & $5(8.2 \%)$ & $9(9.3 \%)$ & $8(9.2 \%)$ & $6(6.6 \%)$ & $1(33.3 \%)$ & $39(7.9 \%)$ \\
\hline \multicolumn{9}{|l|}{ New treatment - no. (\%) } \\
\hline DOAC & $3(50 \%)$ & 8 (47.1\%) & $10(55.5 \%)$ & $15(65.2 \%)$ & $5(23.8 \%)$ & $16(80 \%)$ & $1(50 \%)$ & 58 (54.2\%) \\
\hline VKA & $0(0 \%)$ & $4(23.5 \%)$ & $5(27.8 \%)$ & $5(21.7 \%)$ & $7(33.3 \%)$ & $3(15 \%)$ & $0(0 \%)$ & $24(22.4 \%)$ \\
\hline None & $3(50 \%)$ & $5(29.4 \%)$ & $3(16.7 \%)$ & $3(13 \%)$ & $9(42.9 \%)$ & $1(5 \%)$ & $1(50 \%)$ & $25(23.4 \%)$ \\
\hline
\end{tabular}

Abbreviations: $\mathrm{CrCl}=$ creatinine clearance; $\mathrm{VKA}=$ Vitamin $\mathrm{K}$ antagonists.

In 29 episodes follow up was interrupted before 3 months of DOAC treatment initiation.

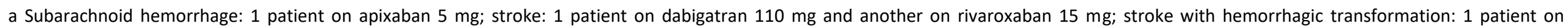
rivaroxaban $15 \mathrm{mg}$.

b All toxicities were related to dabigatran dyspepsia except for one patient who was on apixaban $5 \mathrm{mg}$.

c Other reason for discontinuation: 11 patients => serious clinical condition; 7 patients => dose adjustments, 2 patients => platelet aggregation inhibitors initiation, etc 
According to the summary of product characteristics, the DOACs dose was inappropriate in $23.8 \%$ of episodes ( $22 \%$ were underdosed and $1.8 \%$ overdosed). Underdosing was more frequent with rivaroxaban (31.4\% of episodes) and less frequent with dabigatran (14.9\% of episodes) (Supplementary Table 3).

Table 4 shows DOACs interruption before completion of the study. Seven patients $(1.4 \%)$ were lost to follow-up; Forty-two patients (8.6\%) died, 3 in the context of stroke and 1 in the context of a subarachnoid hemorrhage, being the remaining deaths due to other causes. DOAC treatment was permanently discontinued in 107 episodes (21.8\%) for reasons listed also in Table 4, being the most common bleeding $(4.3 \%)$, worsening of kidney function $(3.3 \%)$, toxicity $(2.4 \%)$, and stroke $(2.2 \%)$. Specifically, $8.8 \%$ episodes with rivaroxaban $20 \mathrm{mg}$ were discontinued because of bleeding and $6.6 \%-7.2 \%$ with dabigatran $110 \mathrm{mg}$ and $150 \mathrm{mg}$, respectively, because of dyspepsia. Over a fifth of episodes with apixaban $2.5 \mathrm{mg}$ were interrupted because of death not related with anticoagulation. When DOACs were discontinued, in most episodes (54.2\%) another DOAC was chosen as alternative treatment.

\subsection{Outcomes}

Rates of stroke and transient ischemic attack for the whole series were 1.64 and 0.54 events/100 patients-years, respectively (Supplementary Table 4). In the 3 patients taking dabigatran $75 \mathrm{mg}$ rates were much higher (24.14 events/100 patients-years). Regarding the rest of the series, rates were higher with rivaroxaban $15 \mathrm{mg}$ and dabigatran $110 \mathrm{mg}$, but the difference did not reach statistical significance ( $\mathrm{p}=0.071$ in the log-rank test) (Supplementary Figure 2).

In the multivariate analysis analyzing time to occurrence of a TE event, prior stroke (RR: 4.229; 95\% CI: 1.517-11.791; $\mathrm{p}=0.006$ ) and age (RR: 1.196; 95\% CI: 1.052-1.359; $\mathrm{p}=0.006$ ) were independently associated with an increased risk of stroke (Table 5).

Table 5: Risk ratios for time to occurrence of a thromboembolic (TE) event (Cox regression model)

\begin{tabular}{lccc}
\hline Variables & Risk ratio & $95 \% \mathrm{Cl}$ & P-value \\
\hline Apixaban 2,5 mg & 0.227 & $0.026-1.999$ & 0.182 \\
Apixaban 5 mg & 1.019 & $0.287-3.624$ & 0.977 \\
Dabigatran $110 \mathrm{mg}$ & 0.414 & $0.103-1.658$ & 0.213 \\
Dabigatran $150 \mathrm{mg}$ & 0.541 & $0.094-3.116$ & 0.491 \\
Rivaroxaban $20 \mathrm{mg} *$ & - & - & - \\
Age & $\mathbf{1 . 1 9 6}$ & $\mathbf{1 . 0 5 2 - 1 . 3 5 9}$ & $\mathbf{0 . 0 0 6}$ \\
Gender (male) & 1.916 & $0.698-5.258$ & 0.207 \\
Creatinine clearance & 1.024 & $0.997-1.052$ & 0.080 \\
Previous thromboembolism & $\mathbf{4 . 2 2 9}$ & $\mathbf{1 . 5 1 7 - 1 1 . 7 9 1}$ & $\mathbf{0 . 0 0 6}$ \\
\hline
\end{tabular}

P-value $<0.05$.

The reference category Rivaroxaban $15 \mathrm{mg}$ was chosen because this treatment group had the highest proportion of TE events.

*In the treatment group Rivaroxaban 20 mg no TE events were observed.

Rates of major, NMCR and intracranial bleeding were 2.4, 5 and 0.5 events/100 patients-years, respectively (Supplementary Table 5). The bleeding origin was more common gastrointestinal and genitourinary 2.6 events/100 patients-years (major: 1.5 and NMCR bleeding: 1.1) and 2.1 events/100 patients-years (major: 0.1 and NMCR bleeding: 1.9), respectively. Rates were higher with dabigatran $110 \mathrm{mg}$, but the difference did not reach statistical significance ( $\mathrm{p}=0.54$ in the log-rank test) (Supplementary Figure 3).

In the multivariate analysis analyzing time to occurrence of a major or NMCR bleeding event, concomitant platelet aggregation inhibitors (RR: 7.052; 95\% CI: 2.277-21.838; $\mathrm{p}=0.001$ ), male gender (RR: 2.096; 95\% CI: 1.180-3.722; $\mathrm{p}=0.0012$ ) and age (RR: 1.072; CI: 1.022-1.125; $\mathrm{p}=0.005$ ) were independently associated with an increased risk of bleeding (Table 6).

Table 6: Risk ratios for time to occurrence of a bleeding event (Cox regression model)

\begin{tabular}{lll}
\hline Variables & Risk ratio & $95 \% \mathrm{Cl}$ \\
\hline
\end{tabular}




\begin{tabular}{lccc}
\hline Apixaban $2,5 \mathrm{mg}$ & 0.243 & $0.051-1.148$ & 0.074 \\
Apixaban $5 \mathrm{mg}$ & 0.959 & $0.382-2.404$ & 0.928 \\
Dabigatran $150 \mathrm{mg}$ & 1.62 & $0.628-4.175$ & 0.318 \\
Rivaroxaban $15 \mathrm{mg}$ & 0.506 & 0.1961 .307 & 0.159 \\
Rivaroxaban $15 \mathrm{mg}$ & 1.544 & $0.591-4.020$ & 0.375 \\
Age & $\mathbf{1 . 0 7 2}$ & $\mathbf{1 . 0 2 2 - 1 . 1 2 5}$ & $\mathbf{0 . 0 0 5}$ \\
Gender (male) & $\mathbf{2 . 0 9 6}$ & $\mathbf{1 . 1 8 0 - 3 . 7 2 2}$ & $\mathbf{0 . 0 1 2}$ \\
Platelet aggregation inhibitors-yes & $\mathbf{7 . 0 5 2}$ & $\mathbf{2 . 2 7 7 - 2 1 . 8 3 8}$ & $\mathbf{0 . 0 0 1}$ \\
\hline
\end{tabular}

P-value $<0.05$.

The reference category dabigatran $150 \mathrm{mg}$ was chosen because this treatment group had the highest proportion of bleeding events.

\section{Discussion}

We present the results of a program for DOACs management in a cohort of 445 patients (490 episodes) with NVAF controlled in routine clinical practice with a pre-planned follow-up for up to 3 years, in the Hematology Service at a single regional hospital in Spain. Three are the main findings of our study, firstly, the observation that despite significant differences in the target population between pivotal studies and daily clinical practice, the key messages of the former in terms of the benefit associated with DOACs remain valid. Secondly, the description of a common pattern of switching between DOACs, and thirdly, the fact that consensus programs are useful for a better assessment of DOAC management.

The use of DOACs in Spain is markedly lower than in other neighboring countries, since reimbursement of prescriptions requires approval by health care authorities. Accordingly, real-world studies evaluating DOACs in the Spanish population are scarce. A few retrospective studies have been published based on databases containing electronic health records $[17,18,19,20,21]$ or prospective registries [11], but most of these studies have focused exclusively on the distribution of the different DOACs/doses prescribed and patients characteristics $[17,18,19,20,21]$ and only a few have analyzed stroke and bleeding events [11,12,13,22]. To our knowledge, the study by Cerda et al. [13], performed in a cohort of 1443 patients from a single center is the only one with a comparable methodology to ours, showing similar basal characteristics and follow-up of our cohort of patients. While in Cerda's study rivaroxaban was the DOAC most commonly prescribed (almost $50 \%$ of all the prescriptions), in our study the different DOACs were well balanced.

Of note, the clinical profile of patients in our series differed according to the DOAC administered. These different profiles do not appear to be random but are in line with recent publications analyzing characteristics of patients prescribed DOAC in routine practice [23,24]. A higher margin in case of renal failure and low gastrointestinal bleeding risk of apixaban in the elderly [3], together with data of the RELY- trial [2], showing a lower risk of ischemic stroke independent of age, but an interaction between age and bleeding risk, might explain differences in prescriptions [25].

Stroke rates in our study (1.6 events/100 patients-years) were similar to those reported in pivotal trials ranging from 1.1 to 1.7 events/100 patients-years. Similarly, rates of major bleeding (2.4/100 patients-years), NMCR bleeding (5/100 patients-years) and intracranial bleeding $(0.5 / 100$ patients-years) in our study were in the range of those reported in randomized trials. Increasing age and previous stroke/TIA were independent predictors of efficacy, in accordance with previous studies $[26,27,28,29,30,31]$

As a whole, patient characteristics in our study differed from pivotal trials. Our population was older and glomerural filtration was worse. Patients older than 80 were well represented in our population and lower doses of all DOACs, except dabigatran, were prescribed in a higher rate than in pivotal trials. Median CHADSVASC was also higher, reflecting the fact that real-world patients present more comorbidities than subjects selected in randomized trials. These differences notwithstanding, our bleeding and thrombotic rates were similar to those in clinical trials. The implications of extending the results of randomized trials to the general population affected by NVAF are far-reaching, especially as a necessary step prior to assess the relative cost-utility of the three DOACs compared with VAK. A recent publication points at the superiority of all three direct anticoagulants against acenocoumarol in 
terms of cost-effectiveness in a Spanish setting [32]. In the absence of scientific evidence based on clinical or economic data, administrative restrictions for DOACs appear to be unnecessary.

It is unknown whether all DOACs have similar rates of switch, or whether some DOACs are more prone to be substituted with another DOAC over time. Information on this matter in the literature is rare, although it is a frequent issue in clinical practice [33]. A distinctive feature of our study is that we analyzed DOACs discontinuation, dose adjustments and patterns of crossover between DOACs. A recent meta-analysis in patients with NVAF reviewed studies comparing DOAC-to-DOAC switch prevalence and compared risk of switch depending on index DOAC, showing that switching across DOACs is frequent, affecting up to $11 \%$ of patients during their life time [34]. Among DOACs, apixaban had lower risk of DOAC-to-DOAC switch compared to dabigatran and rivaroxaban, but no data were available in this study regarding specific causes of switch. Another case series showed a higher cross-over rate with dabigatran [35]. These results resembled our own study, where almost 10\% of patients underwent dose adjustments or switched to another DOAC, with the highest percentages in dabigatran users (13.6\%) and the lowest in patients prescribed apixaban (3.9\%). Furthermore, apixaban was the DOAC most often chosen as an alternative option (the $5 \mathrm{mg}$ dose in $28.5 \%$ and the $2.5 \mathrm{mg}$ dose in $23.8 \%$ of cases). The lower bleeding rate observed with apixaban treatment in comparison to rivaroxaban and dabigatran in multiple real-world studies $[23,24,36,37]$ and its lowest dependance on renal function may influence these treatment decisions.

Risk factors for bleeding during DOACs therapy have yet to be fully elucidated and limited data are available on the clinical value of various bleeding risk scores in this setting, being the HAS-BLED the most widely used score and with the best evidence for predicting bleeding risk [10]. In our study, increasing age, concurrent aspirin use, and male gender were independent predictors of bleeding. Multiple studies have highlighted the increased propensity of bleeding in elderly patients $[7,30,31,38,39]$ and in those taking the combination of oral anticoagulants plus antiplatelet drugs $[39,40,41,42]$. The influence of gender on bleeding rates is more controversial, with some studies confirming our own $[43,44,45]$.

Although no head-to-head comparisons between DOACs have been performed, a series of systematic reviews and meta-analysis of RCT and observational studies, have compared efficacy and safety of DOACs compared with warfarin, with apixaban offering, in general, the most favorable profile $[46,47,48]$. In our study we did not observed statistically significant differences between specific DOAC, neither in the cumulative incidence rate nor in the multivariate analysis for evaluation of stroke/TE or bleeding events. The small sample size in our study might have conferred low power of our analysis to detect differences unless these had been remarkably large.

Concerning evaluation of the appropriateness of dosing, the incidence of off-label use in our study was $23.8 \%$, being underdosing much more common $(22 \%)$ than over-dosing $(1.8 \%)$. This numbers are in line with previous studies reporting non-recommended dosing in up to $30 \%$ of NVAF patients, the majority due to underdosing $[40,49,50,51,52,53]$. A bias towards greater concern of bleeding amongst physicians might be a main underlying factor [54]. It should be taken into consideration, that in real clinical practice appropriateness cannot always be defined straight forward. Some patients with borderline characteristics and dose adjustments deviating from the labeling recommendations, might not always represent an incorrect dose. For instance, in our study 36/56 (64\%) of patients strictly speaking underdosed with rivaroxaban, were older than 80 years and/or had a creatinine clearance between $50-60 \mathrm{ml} / \mathrm{min}$. Due to the small sample size, we did not analyze differences in outcomes in these cases. Although data in this regard have not been consistent, there are concerns for a potential increase of bleeding or TE events in these cases [40,52].

Finally, it must be highlighted that our program for DOACs management in NVAF patients harmonizes with the recently published guidelines of the European Society of Cardiology which emphasize the importance of implementing an integrated care of AF across all healthcare levels and among different specialties (ABC pathway) to maximize treatment safety and efficacy [9]. Although patients on DOACs, unlike those on VKA, need no routine laboratory monitoring, it is essential that anticoagulation clinics get involved and provide guidance surrounding DOACs management. In our opinion centralized follow-up within Hematology Units up should be stratified based on patient risk level for TE/bleeding complications. For the standard risk patient, it should probably be sufficient a 
follow-up for a defined time, while high-risk patients, such as those with recurrent TE events o diminished kidney functioning, might benefit from a prolonged follow-up. Further studies are needed addressing the impact of centralized management of DOACs on quality anticoagulation control or clinical outcomes.

Strengths of our study are first, that clinical and analytic data were collected prospectively, allowing for good data quality, and second, the fact that treatment decisions followed a consensus protocol between acting physicians. The small number of patients and the narrow time of follow-up are limitations of our study

\section{Conclusions}

To conclude, our study complements the scant data available on the use of DOACs in NVAF patients in Spain, confirming a good safety and effectiveness profile, analyzes the pattern of switching between DOACs and offers a solid model based on consensus protocols under the surveillance of specialized Units.

Supplementary Materials: The following are available online at:

Supplementary Table 1: Number of patients and episodes analyzed (www.mdpi.com/xxx/s1, Table S1)

\begin{tabular}{ccc}
\hline $\begin{array}{c}\text { Patients } \\
n=445\end{array}$ & DOAC per patient $(n)$ & $\begin{array}{c}\text { Episodes } \\
n=490\end{array}$ \\
\hline 403 & 1 & 403 \\
40 & 2 & 80 \\
1 & 3 & 3 \\
1 & 4 & 4 \\
\hline
\end{tabular}

Supplementary Table 2. Description of dose adjustments and crossover between DOACs (www.mdpi.com/xxx/s2, Table S2)

\begin{tabular}{|c|c|c|c|}
\hline & \multicolumn{3}{|c|}{ New DOAC prescribed } \\
\hline & Number switching & DOAC & no. \\
\hline Total & $42 / 445(9,4 \%)$ & & \\
\hline Rivaroxaban & $16 / 165(9.7 \%)$ & & \\
\hline \multirow[t]{3}{*}{ Rivaroxaban $20 \mathrm{mg}$} & $12 / 87(13,8 \%)$ & R15 & 7 \\
\hline & & A5 & 4 \\
\hline & & D110 & 1 \\
\hline \multirow[t]{3}{*}{ Rivaroxaban 15 mg } & $4 / 78(5,1 \%)$ & A2.5 & 2 \\
\hline & & A5 & 1 \\
\hline & & $\mathrm{R} 20$ & 1 \\
\hline Dabigatran & $21 / 154(13,6 \%)$ & & \\
\hline \multirow[t]{3}{*}{ Dabigatran $150 \mathrm{mg}$} & $11 / 96(11,4 \%)$ & A5 & 5 \\
\hline & & $\mathrm{R} 20$ & 3 \\
\hline & & D110 & 3 \\
\hline \multirow[t]{4}{*}{ Dabigatran 110 mg } & $8 / 55$ (14.5\%) & A2.5 & 4 \\
\hline & & A5 & 2 \\
\hline & & D150 & 1 \\
\hline & & R15 & 1 \\
\hline Dabigatran $75 \mathrm{mg}$ & $2 / 3(66,6 \%)$ & D110 & 2 \\
\hline Apixaban & $5 / 126(3.9 \%)$ & & \\
\hline \multirow[t]{2}{*}{ Apixaban $5 \mathrm{mg}$} & $5 / 92(5.4 \%)$ & A2.5 & 4 \\
\hline & & R15 & 1 \\
\hline Apixaban $2.5 \mathrm{mg}$ & $0 / 34(0 \%)$ & & \\
\hline
\end{tabular}


Supplementary Table 3: Rate of appropriate dosing (www.mdpi.com/xxx/s3, Table S3)

\begin{tabular}{ccccc} 
& Apixaban & Dabigatran & Rivaroxaban & total \\
\hline $\begin{array}{l}\text { Appropriate dose } \\
\text { Inappropriate dose }\end{array}$ & $122(80.8 \%)$ & $135(83.8)$ & $116(65.2 \%)$ & $373(76 \%)$ \\
Low dose & $28(18.5 \%)$ & $24(14.9 \%)$ & $56(31.4 \%)$ & $108(22 \%)$ \\
High dose & $1(0.9 \%)$ & $2(1.2 \%)$ & $6(3.4 \%)$ & $9(1.8 \%)$ \\
\hline
\end{tabular}


Supplementary Table 4: Rates of thromboembolic events by study group (www.mdpi.com/xxx/s4, Table S4)

\begin{tabular}{|c|c|c|c|c|c|c|c|c|c|c|c|c|c|c|c|c|}
\hline & \multicolumn{2}{|c|}{$\begin{array}{c}\text { Apixaban } \\
2.5 \mathrm{mg} \\
(\mathrm{n}=46)\end{array}$} & \multicolumn{2}{|c|}{$\begin{array}{c}\text { Apixaban } \\
5 \mathrm{mg} \\
(\mathrm{n}=105)\end{array}$} & \multicolumn{2}{|c|}{$\begin{array}{c}\text { Dabigatran } \\
110 \mathrm{mg} \\
(\mathrm{n}=61)\end{array}$} & \multicolumn{2}{|c|}{$\begin{array}{c}\text { Dabigatran } \\
150 \mathrm{mg} \\
(\mathrm{n}=97)\end{array}$} & \multicolumn{2}{|c|}{$\begin{array}{c}\text { Rivaroxaban } \\
15 \mathrm{mg} \\
(\mathrm{n}=87)\end{array}$} & \multicolumn{2}{|c|}{$\begin{array}{c}\text { Rivaroxaban } \\
20 \mathrm{mg} \\
(\mathrm{n}=91)\end{array}$} & \multicolumn{2}{|c|}{$\begin{array}{c}\text { Dabigatran } \\
75 \mathrm{mg} \\
(n=3)\end{array}$} & \multicolumn{2}{|c|}{$\begin{array}{c}\text { Total } \\
(n=490)\end{array}$} \\
\hline & Patients & $n / 100$ & Patients & $n / 100$ & Patients & $n / 100$ & Patients & $n / 100$ & Patients & $n / 100$ & Patients & $n / 100$ & Patients & $n / 100$ & Patients & $n / 100$ \\
\hline & $n$ & $\mathrm{Pt}-\mathrm{Yr}$ & $n$ & $\mathrm{Pt}-\mathrm{Yr}$ & $n$ & $\mathrm{Pt}-\mathrm{Yr}$ & $n$ & $\mathrm{Pt}-\mathrm{Yr}$ & $n$ & Pt-Yr & $n$ & Pt-Yr & $n$ & Pt-Yr & $n$ & $\mathrm{Pt}-\mathrm{Yr}$ \\
\hline Total & 1 & 1.26 & 4 & 2.07 & 4 & 3.67 & 2 & 1.13 & 8 & 4.6 & 0 & 0 & 1 & 24.14 & 20 & 2.18 \\
\hline - Stroke & 0 & 0 & 3 & 1.55 & 4 & 3.67 & 2 & 1.13 & 6 & 3.45 & 0 & 0 & 0 & 0 & 15 & 1.64 \\
\hline - TIA & 1 & 1.26 & 1 & 0.52 & 0 & 0 & 0 & 0 & 2 & 1.15 & 0 & 0 & 1 & 24.14 & 5 & 0.54 \\
\hline
\end{tabular}

Abbreviations: $\mathrm{Pt}-\mathrm{Yr}=$ number of events per 100 patients-years of follow-up; TIA = transient ischemic attack.

Data are shown for treatment episodes with one or more events (one patient on rivaroxaban $15 \mathrm{mg}$ suffered a TIA and subsequently a stroke).

No systemic thromboembolisms were observed

Supplementary Table 5: Rates of major and non-major clinically relevant (NMCR) bleeding events by study group (www.mdpi.com/xxx/s5, Table S5)

\begin{tabular}{|c|c|c|c|c|c|c|c|}
\hline $\begin{array}{c}\text { Apixaban } \\
2.5 \mathrm{mg} \\
(\mathrm{n}=46)\end{array}$ & $\begin{array}{c}\text { Apixaban } \\
5 \mathrm{mg} \\
(\mathrm{n}=105)\end{array}$ & $\begin{array}{c}\text { Dabigatran } \\
110 \mathrm{mg} \\
(\mathrm{n}=61)\end{array}$ & $\begin{array}{c}\text { Dabigatran } \\
150 \mathrm{mg} \\
(\mathrm{n}=97)\end{array}$ & $\begin{array}{c}\text { Rivaroxaban } \\
15 \mathrm{mg} \\
(\mathrm{n}=87)\end{array}$ & $\begin{array}{c}\text { Rivaroxaban } \\
20 \mathrm{mg} \\
(\mathrm{n}=91)\end{array}$ & $\begin{array}{c}\text { Dabigatran } \\
75 \mathrm{mg} \\
(n=3)\end{array}$ & $\begin{array}{c}\text { Total } \\
(n=490)\end{array}$ \\
\hline $\begin{array}{ll}n \mathrm{n} & \mathrm{n} / 100 \\
& \mathrm{Pt}-\mathrm{Yr}_{\mathrm{r}}\end{array}$ & $\begin{array}{ll}n & n / 100 \\
& P t-Y r\end{array}$ & $\begin{array}{cc}\mathrm{n} & \mathrm{n} / 100 \\
& \mathrm{Pt}-\mathrm{Yr}\end{array}$ & $\begin{array}{ll}n & n / 100 \\
& P t-Y r\end{array}$ & $\begin{array}{ll}n & n / 100 \\
& P t-Y r\end{array}$ & $\begin{array}{ll}n & n / 100 \\
& P t-Y r\end{array}$ & $\begin{array}{cc}\mathrm{n} & \mathrm{n} / 100 \\
& \mathrm{Pt}-\mathrm{Yr}\end{array}$ & \\
\hline
\end{tabular}

\begin{tabular}{|c|c|c|c|c|c|c|c|c|c|c|c|c|c|c|c|c|}
\hline $\begin{array}{l}\text { incidence rate of a first major and NMCR } \\
\text { bleeding event }\end{array}$ & 2 & $(2,5)$ & 11 & $(5,7)$ & 10 & $(9,2)$ & 13 & $(7,4)$ & 9 & (5.2) & 12 & $(6,6)$ & 0 & (0) & 57 & $(6,2)$ \\
\hline $\begin{array}{l}\text { Incidence rate of any major and NMCR } \\
\text { bleeding event }{ }^{\mathrm{a}}\end{array}$ & 5 & (6.3) & 12 & (6.2) & 11 & (10.1) & 15 & $(8,5)$ & 9 & $(5,2)$ & 16 & (8.7) & 0 & (0) & 68 & $(7,4)$ \\
\hline Major bleeding & 4 & (5) & 4 & (2.1) & 2 & (1.8) & 4 & (2.3) & 6 & (3.5) & 2 & (1.1) & 0 & (0) & 22 & (2.4) \\
\hline NMCR bleeding & 1 & (1.3) & 8 & (4.1) & 9 & (8.3) & 11 & (6.2) & 3 & (1.7) & 14 & (7.6) & 0 & (0) & 46 & (5) \\
\hline Location & & & & & & & & & & & & & & & & \\
\hline Total & $5 *$ & (6.3) & 3 & (1.5) & 5 & (4.6) & 4 & (2.3) & 3 & (1.7) & 4 & (2.2) & - & - & 24 & (2.6) \\
\hline Gastrointestinal & 4 & (5) & 2 & (1.1) & 1 & $(0.9)$ & 3 & (1.7) & 2 & (1.1) & 2 & (1.1) & - & - & 14 & (1.5) \\
\hline NMCR & 1 & (1.3) & 1 & $(0.5)$ & 4 & (3.7) & 1 & $(0.6)$ & 1 & $(0.6)$ & 2 & (1.1) & - & - & 10 & (1.1) \\
\hline Total & - & - & 2* & (1.1) & 4 & (3.7) & 6* & (3.4) & 1 & (0.6) & 6* & (3.3) & - & - & 19 & (2.1) \\
\hline Genitourinary & - & - & - & - & 1 & $(0.9)$ & - & - & - & - & - & - & - & - & 1 & (0.1) \\
\hline
\end{tabular}




\begin{tabular}{|c|c|c|c|c|c|c|c|c|c|c|c|c|c|c|c|c|c|c|}
\hline & & NMCR & - & - & 2 & (1.1) & 3 & $(2.7)$ & 6 & (3.4) & 1 & $(0.6)$ & 6 & (3.3) & & - & 18 & (1.9) \\
\hline & Cranial & Total (all major) & - & - & $2^{*}$ & (1.1) & - & - & - & - & $3^{*}$ & (1.7) & - & - & - & - & 5 & (0.5) \\
\hline & Epistaxis & Total (all NMCR) & - & - & 3 & (1.5) & - & - & 1 & $(0.6)$ & - & - & - & - & - & - & 4 & $(0.4)$ \\
\hline Hemoptysis & & Total (all NMCR & - & - & - & - & - & - & 1 & $(0.6)$ & - & - & 3 & (1.6) & - & - & 4 & (0.4) \\
\hline & muscular & Total (all NMCR & - & - & - & - & 1 & (0.9) & - & - & 1 & $(0.6)$ & - & - & - & - & 2 & $(0.2)$ \\
\hline Conjunctival & & Total (all NMCR & - & - & 1 & $(0.5)$ & - & - & 1 & $(0.6)$ & - & - & - & - & - & - & 2 & $(0.2)$ \\
\hline gingivorrhagia & & Total (all NMCR & - & - & - & - & - & - & 1 & $(0.6)$ & - & - & 1 & $(0.5)$ & - & - & 2 & $(0.2)$ \\
\hline & ecchymosis & Total (all NMCR & - & - & - & - & 1 & $(0.9)$ & - & - & - & - & - & - & - & - & 1 & $(0.1)$ \\
\hline & Other & Total (all NMCR & & & 1 & $(0.5)$ & & & 1 & $(0.6)$ & & & 2 & (1.1) & & & 5 & (0.5) \\
\hline
\end{tabular}

A dash (-) represents that there were no patients with events.

a Several events, when they occur, are counted in the same episode within the period under study (5 patients each experienced 2 major/NMCR bleedings, 1 patient experienced 3 major/NMCR

bleedings and 1 patient experienced 4 major/NMCR bleedings during the study period).

* Includes patients with repeated events for episode in the same location due to an underlying bleeding pathology e.g.radiation proctitis and bladder, uterine or prostate cancer 
Supplementary Figure 1: Study Flow diagram (www.mdpi.com/xxx/s5, Figure S1)

\begin{tabular}{|c|c|c|c|c|c|c|}
\hline \multicolumn{2}{|c|}{ 1st DOAC } & \multicolumn{2}{|c|}{ 2nd DOAC } & \multicolumn{2}{|c|}{ 3rd DOAC } & 4th DOAC \\
\hline DOAC & $n=445$ & DOAC & $n=42$ & DOAC & $\mathrm{n}=2$ & $\mathrm{n}=1$ \\
\hline Dabigatran 150 mg & 96 & Apixaban 5 mg & 12 & Apixaban $2.5 \mathrm{mg}$ & 1 & Apixaban $2.5 \mathrm{mg}$ \\
\hline Apixaban 5 mg & 92 & Apixaban $2.5 \mathrm{mg}$ & 10 & Apixaban 5 mg & 1 & \\
\hline Rivaroxaban 20 mg & 87 & Rivaroxaban 15 mg & 9 & & & \\
\hline Rivaroxaban 15 mg & 78 & Dabigatran 110 mg & 6 & & & \\
\hline Dabigatran 110 mg & 55 & Rivaroxaban 20 mg & 4 & & & \\
\hline Apixaban $2.5 \mathrm{mg}$ & 34 & Dabigatran 150 mg & 1 & & & \\
\hline Dabigatran 75 mg & 3 & & & & & \\
\hline
\end{tabular}

Supplementary Figure 2: Cumulative incidence curves (Kaplan-Meier) for the evaluation of risk of thromboembolic events by study groups. (www.mdpi.com/xxx/s2, Figure S2)

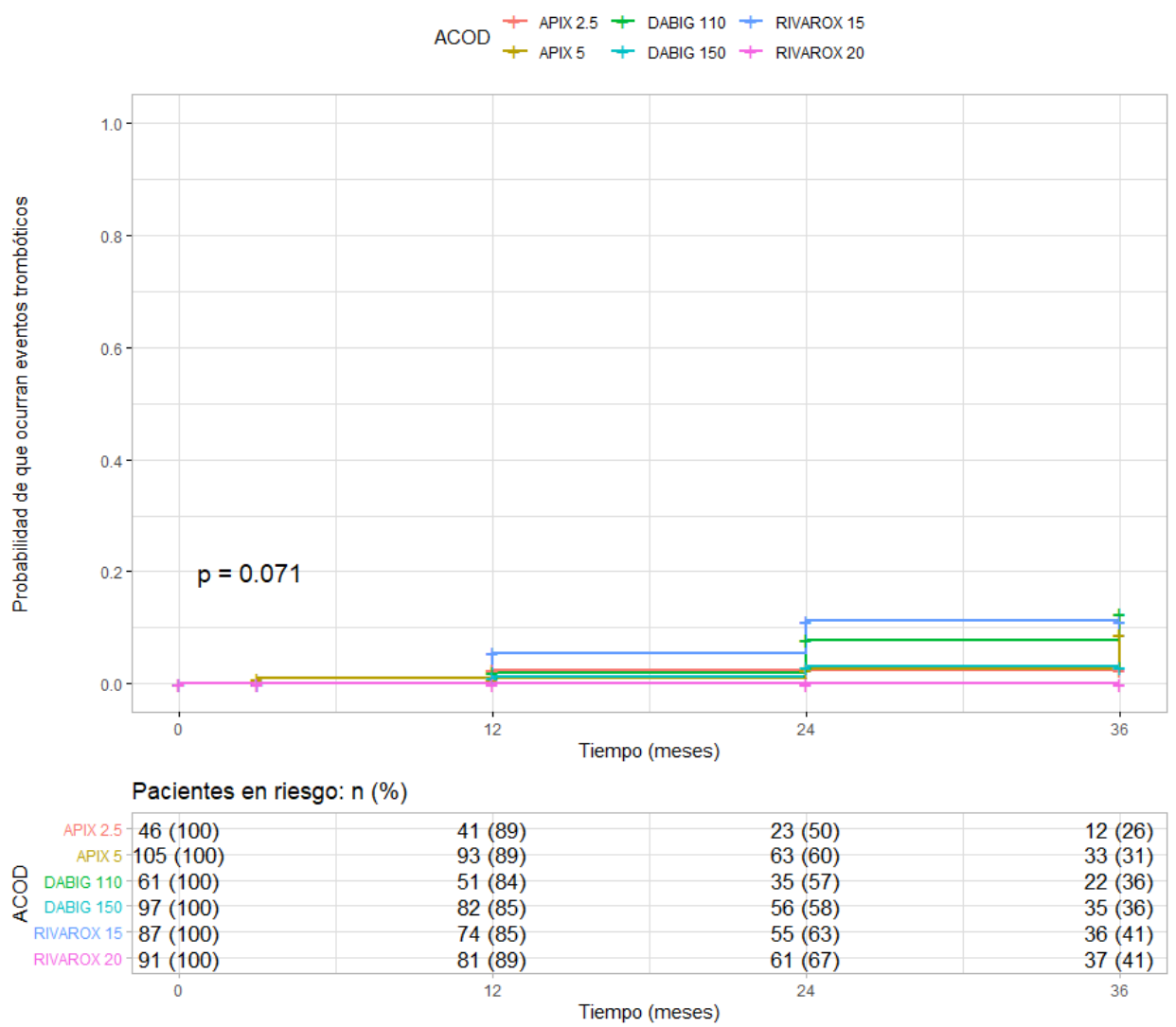

There were not statistically significant differences between specific DOACs ( $p$-value log-rank test, Mantel Cox: 0.071). * analysis was based on time to the firs event (only 1 of the 490 episodes analyzed had more than one TE for episode).

**Patients on treatment with dabigatran $75 \mathrm{mg}$ were excluded from the analysis since being only 3 patients were insufficient for statistical estimations.

Supplementary Figure 3: Cumulative incidence curves (Kaplan-Meir) for the evaluation of risk of major and non-major clinically relevant (NMCR) bleeding events by study groups. (www.mdpi.com/xxx/s3, Figure S3) 


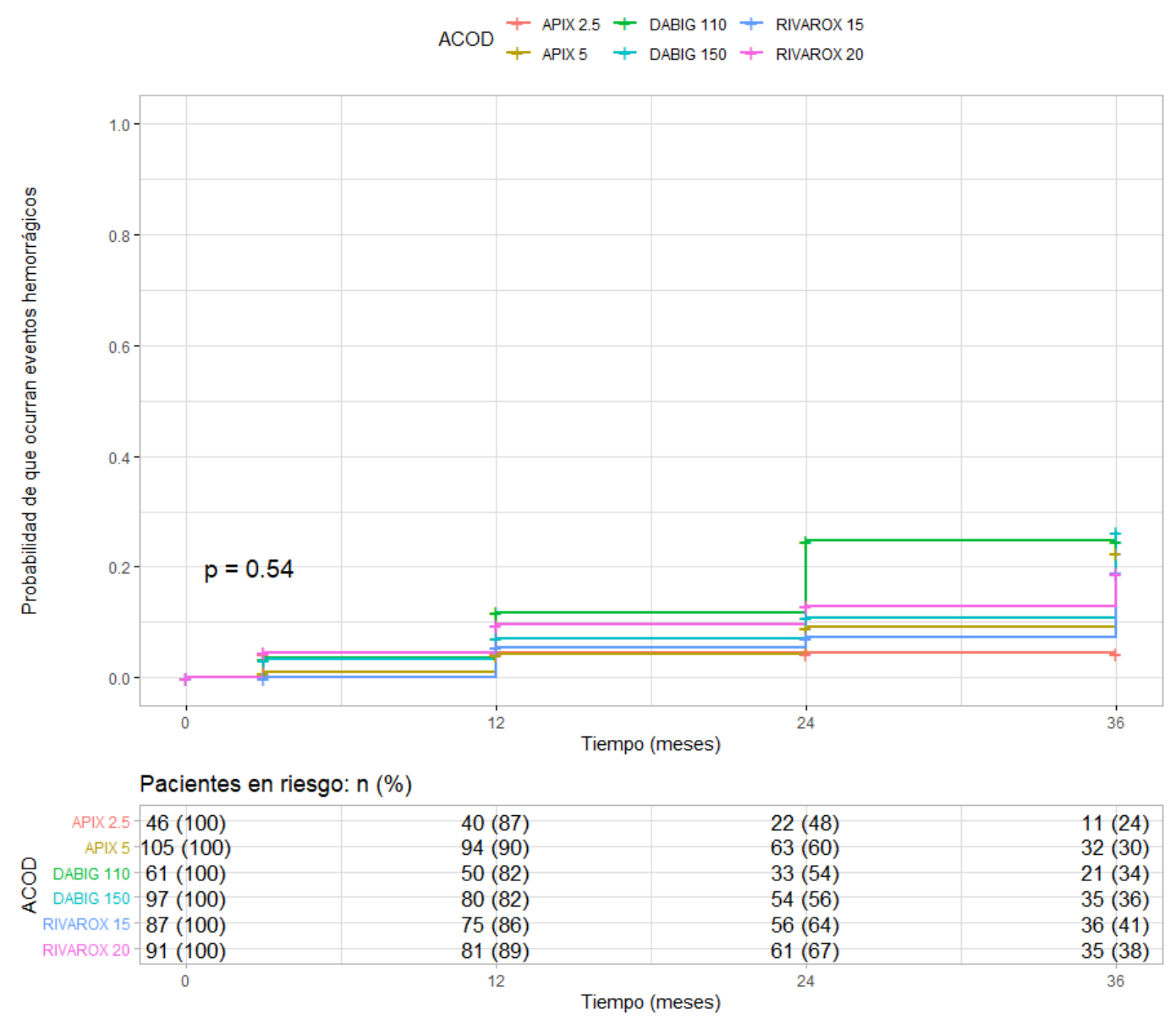

There were not statistically significant differences between specific DOACs ( $p$-value log-rank test, Mantel Cox: 0.54). * Analysis was based on time to the firs event (only 8 of the 490 episodes analyzed had more than one bleeding event for episode).

**Patients on treatment with dabigatran $75 \mathrm{mg}$ were excluded from the analysis since being only 3 patients were insufficient for statistical estimation.

Author Contributions: Conceptualization, ACT, MIO, ER; Data curation, MIO, MAS, MTG, MJA, ING, ICV, ACT; Investigation, ACT, ER; Methodology, ACT, ER, MIO; Resources, ACT and ER; Software, ACT and ER; Supervision, ACT, ER, MIO; Validation, ACT and ER; Visualization, ACT; Writing - original draft, ACT and ER; Writing - review \& editing, ACT and ER.; funding acquisition, none. All authors have read and agreed to the published version of the manuscript.

Funding: This research received no external funding.

Acknowledgments: We gratefully acknowledge all the investigators who participate in the data management, especially those colleagues of the Laboratory Department. The authors declare that there are no conflicts of interest.

Conflicts of Interest: The authors declare no conflict of interest.

Bibliography:

1 Apenteng, P. N., Murray, E. T., Holder, R., Hobbs, F. D. R., \& Fitzmaurice, D. A. (2013). An international longitudinal registry of patients with atrial fibrillation at risk of stroke (GARFIELD): The UK protocol. BMC Cardiovascular Disorders, 13. https://doi.org/10.1186/1471-2261-13-31. 
2 Connolly, S. J., Ezekowitz, M. D., Yusuf, S., Eikelboom, J., Oldgren, J., Parekh, A., et al. (2009). Dabigatran versus Warfarin in Patients with Atrial Fibrillation. New England Journal of Medicine, 361(12), 11391151. https://doi.org/10.1056/nejmoa0905561.

${ }^{3}$ Granger, C. B., Alexander, J. H., McMurray, J. J. V., Lopes, R. D., Hylek, E. M., Hanna, M., et al. (2011). Apixaban versus Warfarin in Patients with Atrial Fibrillation. New England Journal of Medicine, 365(11), 981-992. https://doi.org/10.1056/nejmoa1107039.

${ }^{4}$ Patel, M. R., Mahaffey, K. W., Garg, J., Pan, G., Singer, D. E., Hacke, W., Breithardt, G., Halperin, J. L., Hankey, G. J., Piccini, J. P., Becker, R. C., Nessel, C. C., Paolini, J. F., Berkowitz, S. D., Fox, K. A. A., \& Califf, R. M. (2011). Rivaroxaban versus Warfarin in Nonvalvular Atrial Fibrillation. New England Journal of Medicine, 365(10), 883-891. https://doi.org/10.1056/nejmoa1009638.

5 Carmo, J., Costa, F. M., Ferreira, J., \& Mendes, M. (2016). Dabigatran in real-world atrial fibrillation: Meta-analysis of observational comparison studies with vitamin $\mathrm{K}$ antagonists. Thrombosis and Haemostasis, 116(4), 754-763. https://doi.org/10.1160/TH16-03-0203.

${ }^{6}$ Huisman, M. v., Rothman, K. J., Paquette, M., Teutsch, C., Diener, H. C., Dubner, S. J., et al. (2018). Two-year follow-up of patients treated with dabigatran for stroke prevention in atrial fibrillation: Global Registry on Long-Term Antithrombotic Treatment in Patients with Atrial Fibrillation (GLORIA-AF) registry. American Heart Journal, 198, 55-63. https://doi.org/10.1016/j.ahj.2017.08.018

7 Camm, A. John, Amarenco, P., Haas, S., Hess, S., Kirchhof, P., Kuhls, S., van Eickels, M., \& Turpie, A. G. G. (2016). XANTUS: A real-world, prospective, observational study of patients treated with rivaroxaban for stroke prevention in atrial fibrillation. European Heart Journal, 37(14), 1145-1153. https://doi.org/10.1093/eurheartj/ehv466.

8 Li, X., Deitelzweig, S., Keshishian, A., Hamilton, M., Horblyuk, R., Gupta, K. et al. (2017). Effectiveness and safety of apixaban versus warfarin in non-valvular atrial fibrillation patients in "real-world" clinical practice: A propensity-matched analysis of 76,940 patients. Thrombosis and Haemostasis, 117(6), 10721082. https://doi.org/10.1160/TH17-01-0068

9 Kirchhof, P., Benussi, S., Kotecha, D., Ahlsson, A., Atar, D., Casadei, B., et al. (2016). 2016 ESC Guidelines for the management of atrial fibrillation developed in collaboration with EACTS. In European Heart Journal (Vol. 37, Issue 38). Oxford University Press. https://doi.org/10.1093/eurheartj/ehw210.

${ }^{10}$ Hindricks G, Potpara T, Dagres N, Arbelo E, Bax JJ, Blomström-Lundqvist C, et al. ESC Scientific Document Group. 2020 ESC Guidelines for the diagnosis and management of atrial fibrillation developed in collaboration with the European Association for Cardio-Thoracic Surgery (EACTS): The Task Force for the diagnosis and management of atrial fibrillation of the European Society of Cardiology (ESC) Developed with the special contribution of the European Heart Rhythm Association (EHRA) of the ESC. Eur Heart J. 2021 Feb 1;42(5):373-498. doi: 10.1093/eurheartj/ehaa612.

11 Anguita Sánchez, M., Bertomeu Martínez, V., Ruiz Ortiz, M., Cequier Fillat, Á., Roldán Rabadán, I., Muñiz García, J., et al. (2020). Direct oral anticoagulants versus vitamin K antagonists in real-world patients with nonvalvular atrial fibrillation. The FANTASIIA study. Revista Española de Cardiología (English Edition), 73(1), 14-20. https://doi.org/10.1016/j.rec.2019.02.021.

12 Ramagopalan, S. v., Sicras-Mainar, A., Polanco-Sanchez, C., Carroll, R., \& de Bobadilla, J. F. (2019). Patient characteristics and stroke and bleeding events in nonvalvular atrial fibrillation patients treated with apixaban and Vitamin K antagonists: A Spanish real-world study. Journal of Comparative Effectiveness Research, 8(14), 1201-1212. https://doi.org/10.2217/cer-2019-0079 
13 Cerdá, M., Cerezo-Manchado, J. J., Johansson, E., Martínez, F., Fernández, M., Varela, A., et al. (2019). Facing real-life with direct oral anticoagulants in patients with nonvalvular atrial fibrillation: Outcomes from the first observational and prospective study in a Spanish population. Journal of Comparative Effectiveness Research, 8(3), 165-178. https://doi.org/10.2217/cer-2018-0134.

14 Kaatz, S., Ahmad, D., Spyropoulos, A. C., \& Schulman, S. (2015). Definition of clinically relevant non-major bleeding in studies of anticoagulants in atrial fibrillation and venous thromboembolic disease in non-surgical patients: Communication from the SSC of the ISTH. Journal of Thrombosis and Haemostasis, 13(11), 2119-2126. https://doi.org/10.1111/jth.13140

15 R Core Team (2021). R: A language and environment for statistical computing. R Foundation for Statistical Computing, Vienna, Austria. URL https://www.R-project.org/.

${ }_{16}$ Benjamini, Y., \& Hochberg, Y. (1995). Controlling the False Discovery Rate: A Practical and Powerful Approach to Multiple Testing. Journal of the Royal Statistical Society. Series B (Methodological), 57(1), 289-300. Retrieved July 19, 2021, from http://www.jstor.org/stable/2346101.

17 de la Figuera, M., Prieto, M. A., Marín, N., Egocheaga, I., \& Cinza, S. (2017). Diferencias en el manejo de los pacientes con fibrilación auricular según inicie el tratamiento con anticoagulantes orales de acción directa el médico de atención primaria o el especialista. Estudios SILVER-AP y BRONCE-AP. Semergen, 44(5). https://doi.org/10.1016/j.semerg.2017.09.005.

18 de la Figuera, M., Cinza, S., Marín, N., Egocheaga, I., \& Prieto, M. A. (2018). Clinical characteristics of patients with atrial fibrillation treated with direct oral anticoagulants attended in primary care setting. The SILVER-AP study. Atencion Primaria, 50(6), 359-367. https://doi.org/10.1016/j.aprim.2017.05.009.

${ }^{19}$ Gomez-Lumbreras, A., Cortes, J., Giner-Soriano, M., Quijada-Manuitt, M. A., \& Morros, R. (2018). Characteristics of Apixaban-Treated Patients, Evaluation of the Dose Prescribed, and the Persistence of Treatment: A Cohort Study in Catalonia. Journal of Cardiovascular Pharmacology and Therapeutics, 23(6), 494501. https://doi.org/10.1177/1074248418778544.

${ }^{20}$ Mostaza, J. M., Suárez Fernández, C., Castilla Guerra, L., Suriñach, J. M., Tamarit, J. Jet al. (2018). Type and doses of oral anticoagulants and adherence to anticoagulant treatment in elderly patients with atrial fibrillation: The ESPARTA study. Journal of Comparative Effectiveness Research, 7(3), 223-232. https://doi.org/10.2217/cer-2017-0034.

${ }^{21}$ Peris Vidal que falta Peris Vidal J, Ferreiro Argüelles M, Hidalgo Urbano RJ, et al. Patients with non-valvular atrial fibrillation treated with rivaroxaban in Spain: unequal access to oral direct anticoagulants (HEROIC study). Cardiocore. 2018;53(4), 159-165.

22 Rodríguez-Bernal, C. L., Santa-Ana-Téllez, Y., García-Sempere, A., Hurtado, I., Peiró, S., \& Sanfélix-Gimeno, G. (2021). Clinical outcomes of nonvitamin K oral anticoagulants and acenocoumarol for stroke prevention in contemporary practice: A population-based propensity-weighted cohort study. British Journal of Clinical Pharmacology, 87(2), 632-643. https://doi.org/10.1111/bcp.14430.

${ }^{23}$ Rutherford, O. C. W., Jonasson, C., Ghanima, W., Söderdahl, F., \& Halvorsen, S. (2020). Comparison of dabigatran, rivaroxaban, and apixaban for effectiveness and safety in atrial fibrillation: A nationwide cohort study. European Heart Journal - Cardiovascular Pharmacotherapy, 6(2), 75-85. https://doi.org/10.1093/ehjcvp/pvz086.

${ }^{24}$ van Ganse, E., Danchin, N., Mahé, I., Mahé, I., Hanon, O. et al. (2020). Comparative Safety and Effectiveness of Oral Anticoagulants in Nonvalvular Atrial Fibrillation: The NAXOS Study. Stroke, 51(7), 2066-2075. https://doi.org/10.1161/STROKEAHA.120.028825. 
${ }^{25}$ Grymonprez, M., Steurbaut, S., de Backer, T. L., Petrovic, M., Lahousse, L., Noordam, R., Mueller, T., Laranjeira, L., \& Lilly, E. (2020). Effectiveness and Safety of Oral Anticoagulants in Older Patients With Atrial Fibrillation: A Systematic Review and Meta-Analysis. Front. Pharmacol, 11, 583311. https://doi.org/10.3389/fphar.2020.583311.

${ }^{26}$ Marinigh, R., Lip, G. Y. H., Fiotti, N., Giansante, C., \& Lane, D. A. (2010). Age as a risk factor for stroke in atrial fibrillation patients: Implications for thromboprophylaxis. In Journal of the American College of Cardiology (Vol. 56, Issue 11, pp. 827-837). Elsevier USA. https://doi.org/10.1016/j.jacc.2010.05.028.

27 Olesen, J. B., Lip, G. Y. H., Hansen, M. L., Hansen, P. R., Tolstrup, J. S., Lindhardsen, J., et al. (2011). Validation of risk stratification schemes for predicting stroke and thromboembolism in patients with atrial fibrillation: Nationwide cohort study. BMJ, 342(7792), 320. https://doi.org/10.1136/bmj.d124.

${ }^{28}$ Hijazi, Z., Lindbäck, J., Alexander, J. H., Hanna, M., Held, C., Hylek, E. Met al. (2016). The ABC (age, biomarkers, clinical history) stroke risk score: A biomarker-based risk score for predicting stroke in atrial fibrillation. European Heart Journal, 37(20), 1582-1590. https://doi.org/10.1093/eurheartj/ehw054.

${ }^{29}$ Kim, T. H., Yang, P. S., Yu, H. T., Jang, E., Uhm, J. S., Kim, J. Y., et al. (2018). Age threshold for ischemic stroke risk in atrial fibrillation cohort data covering the entire Korean population. Stroke, 49(8), 1872 1879. https://doi.org/10.1161/STROKEAHA.118.021047.

30 Graham, D. J., Reichman, M. E., Wernecke, M., Hsueh, Y. H., Izem, R., Southworth, M. R., et al. (2016). Stroke, bleeding, and mortality risks in elderly medicare beneficiaries treated with dabigatran or rivaroxaban for nonvalvular atrial fibrillation. JAMA Internal Medicine, 176(11), 1662-1671. https://doi.org/10.1001/jamainternmed.2016.5954.

31 Patti, G., Lucerna, M., Pecen, L., Siller-Matula, J. M., Cavallari, I., Kirchhof, P., \& de Caterina, R. (2017). Thromboembolic Risk, Bleeding Outcomes and Effect of Different Antithrombotic Strategies in Very Elderly Patients With Atrial Fibrillation: A Sub-Analysis From the PREFER in AF (PREvention oF Thromboembolic Events-European Registry in Atrial Fibrillation). Journal of the American Heart Association, 6(7). https://doi.org/10.1161/JAHA.117.005657.

32 Monreal-Bosch M, Soulard S, Crespo C, Brand S, Kansal A. Comparacion del coste-utilidad de los anticoagulantes orales de accion directa en la prevencion de ictus en la fibrilacion auricular no valvular en España (Comparison of the cost-utility of direct oral anticoagulants for the prevention of stroke in patients with atrial fibrillation in Spain). Rev Neurol. 2017 Mar 16;64(6):247-256. Spanish. PMID: 28272725.

33 Manzoor, B. S., Walton, S. M., Sharp, L. K., Galanter, W. L., Lee, T. A., \& Nutescu, E. A. (2017). High number of newly initiated direct oral anticoagulant users switch to alternate anticoagulant therapy. Journal of Thrombosis and Thrombolysis, 44(4), 435-441. https://doi.org/10.1007/s11239-017-1565-2

34 Romoli, M., Marchetti, G., Bernardini, F., \& Urbinati, S. (2021). Switching between direct oral anticoagulants: a systematic review and meta-analysis. Journal of Thrombosis and Thrombolysis. https://doi.org/10.1007/s11239-020-02367-2.

35 Marchetti G, Bernardini F, Romoli M, Urbinati S. Switching across direct oral anticoagulants: a real-life-setting pilot prospective study. J Cardiovasc Med (Hagerstown). 2021 Jun 1;22(6):453-458. doi: 10.2459/JCM.0000000000001118. PMID: 33186238.

36 Yao, X., Abraham, N. S., Sangaralingham, L. R., Bellolio, M. F., McBane, R. D., Shah, et al. (2016). Effectiveness and safety of dabigatran, rivaroxaban, and apixaban versus warfarin in nonvalvular atrial fibrillation. Journal of the American Heart Association, 5(6). https://doi.org/10.1161/JAHA.116.003725. 
37 Staerk, L., Gerds, T. A., Lip, G. Y. H., Ozenne, B., Bonde, A. N., Lamberts, M., et al. (2018). Standard and reduced doses of dabigatran, rivaroxaban and apixaban for stroke prevention in atrial fibrillation: a nationwide cohort study. Journal of Internal Medicine, 283(1), 45-55. https://doi.org/10.1111/joim.12683.

38 Tamayo, S., Peacock, W. F., Patel, M., Sicignano, N., Hopf, K. P., Fields, L. E. et al. (2015). Characterizing major bleeding in patients with nonvalvular atrial fibrillation: A pharmacovigilance study of 27467 patients taking Rivaroxaban. Clinical Cardiology, 38(2), 63-68. https://doi.org/10.1002/clc.22373.

39 Akhtar, T., Fratti, J. D. C., Mattumpuram, J., Fugar, S., Uprety, A., Nwaichi, C., et al. (2020). Factors associated with bleeding events in patients on rivaroxaban for non-valvular atrial fibrillation: A real-world experience. International Journal of Cardiology, 320, 78-82. https://doi.org/10.1016/j.ijcard.2020.06.032.

40 Steinberg, B. A., Shrader, P., Thomas, L., Ansell, J., Fonarow, G. C., Gersh, B. J., Kowey, P. R., Mahaffey, K. W., Naccarelli, G., Reiffel, J., Singer, D. E., Peterson, E. D., \& Piccini, J. P. (2016). Off-Label Dosing of Non-Vitamin K Antagonist Oral Anticoagulants and Adverse Outcomes: The ORBIT-AF II Registry. Journal of the American College of Cardiology, 68(24), 2597-2604. https://doi.org/10.1016/j.jacc.2016.09.966

${ }^{41}$ Kumar, S., Danik, S. B., Altman, R. K., Barrett, C. D., Lip, G. Y. H., Chatterjee, S., et al. (2016). Non-Vitamin K Antagonist Oral Anticoagulants and Antiplatelet Therapy for Stroke Prevention in Patients with Atrial Fibrillation: A Meta-Analysis of Randomized Controlled Trials. In Cardiology in Review (Vol. 24, Issue 5, pp. 218-223). Lippincott Williams and Wilkins. https://doi.org/10.1097/CRD.0000000000000088.

42 Lemesle, G., Ducrocq, G., Elbez, Y., van Belle, E., Goto, S., Cannon, C. P., Bauters, C., Bhatt, D. L., \& Steg, P. G. (2017). Vitamin K antagonists with or without long-term antiplatelet therapy in outpatients with stable coronary artery disease and atrial fibrillation: Association with ischemic and bleeding events. Clinical Cardiology, 40(10), 932-939. https://doi.org/10.1002/clc.22750.

43 Raccah BH, Perlman A, Zwas DR, Hochberg-Klein S,Masarwa R,MuszkatM, et al. Gender Differences in efficacy and safety of direct oral anticoagulants in atrial fibrillation: systematic review and network meta-analysis. Ann Pharmacother. (2018) 52:1135-42. doi: 10.1177/1060028018771264.

${ }^{44}$ Goodman SG, Wojdyla DM, Piccini JP, et al. Factors asociated with major bleeding events: insights from the ROCKET AF trial (rivaroxaban once-daily oral direct factor Xa inhibition compared with vitamin $\mathrm{K}$ antagonism for prevention of stroke and embolism trial in atrial fibrillation). J Am Coll Cardiol. 2014;63:891-900. doi:10.1016/j.jacc.2013.11.013.

45 Vinereanu D, Stevens SR, Alexander JH, et al. Clinical outcomes in patients with atrial fibrillation according to sex during anticoagulation with apixaban or warfarin: a secondary analysis of a randomized controlled trial. Eur Heart J. 2015;36:3268-3275. doi:10.1093/eurheartj/ehv447.

46 Ntaios, G., Papavasileiou, V., Makaritsis, K., Vemmos, K., Michel, P., \& Lip, G. Y. H. (2017). Real-World Setting Comparison of Nonvitamin-K Antagonist Oral Anticoagulants Versus Vitamin-K Antagonists for Stroke Prevention in Atrial Fibrillation: A Systematic Review and Meta-Analysis. Stroke, 48(9), 2494-2503. https://doi.org/10.1161/STROKEAHA.117.017549.

47 Malik, A. H., Yandrapalli, S., Aronow, W. S., Panza, J. A., \& Cooper, H. A. (2019). Meta-Analysis of Direct-Acting Oral Anticoagulants Compared With Warfarin in Patients > 75 Years of Age. In American Journal of Cardiology (Vol. 123, Issue 12, pp. 2051-2057). Elsevier Inc. https://doi.org/10.1016/j.amjcard.2019.02.060.

48 Menichelli, D., del Sole, F., di Rocco, A., Farcomeni, A., Vestri, A., Violi, F., et al. (2021). Real-world safety and efficacy of direct oral anticoagulants in atrial fibrillation: a systematic review and meta-analysis of 605771 patients. European Heart Journal - Cardiovascular Pharmacotherapy, 7(FI1), f11-f19. https://doi.org/10.1093/ehjcvp/pvab002. 
49 Yao, X., Shah, N. D., Sangaralingham, L. R., Gersh, B. J., \& Noseworthy, P. A. (2017). Non-Vitamin K Antagonist Oral Anticoagulant Dosing in Patients With Atrial Fibrillation and Renal Dysfunction. Journal of the American College of Cardiology, 69(23), 2779-2790. https://doi.org/10.1016/j.jacc.2017.03.600.

50 Sato, T., Aizawa, Y., Fuse, K., Fujita, S., Ikeda, Y., Kitazawa, H., et al. (2018). The Comparison of Inappropriate-Low-Doses Use among 4 Direct Oral Anticoagulants in Patients with Atrial Fibrillation: From the Database of a Single-Center Registry. Journal of Stroke and Cerebrovascular Diseases, 27(11), 3280-3288. https://doi.org/10.1016/j.jstrokecerebrovasdis.2018.07.028.

${ }^{51}$ Ruiz Ortiz, M., Muñiz, J., Míguez, P. R., Roldán, I., Marín, F., Esteve-Pastor, M. A., Cequier, A., Martínez-Sellés, M., Bertomeu, V., \& Anguita, M. (2018). Inappropriate doses of direct oral anticoagulants in real-world clinical practice: Prevalence and associated factors. A subanalysis of the FANTASIIA registry. Europace, 20(10), 15771583. https://doi.org/10.1093/europace/eux316.

52 Camm, A.J., Cools, F., Virdone, S., Bassand, J. P., Fitzmaurice, D. A., Arthur Fox, et al. (2020). Mortality in Patients With Atrial Fibrillation Receiving Nonrecommended Doses of Direct Oral Anticoagulants. Journal of the American College of Cardiology, 76(12), 1425-1436. https://doi.org/10.1016/j.jacc.2020.07.045

53 Sugrue, A., Sanborn, D., Amin, M., Farwati, M., Sridhar, H., Ahmed, A., et al. (2021). Inappropriate Dosing of Direct Oral Anticoagulants in Patients with Atrial Fibrillation. American Journal of Cardiology, 144, 52-59. https://doi.org/10.1016/j.amjcard.2020.12.062.

${ }^{54}$ Devereaux, P. J., Anderson, D. R., Gardner, M. J., Putnam, W., Flowerdew, G. J., Brownell, B. F., et al. (2001). Differences between perspectives of physicians and patients on anticoagulation in patients with atrial fibrillation: Observational study. British Medical Journal, 323(7323), 1218-1221.

https://doi.org/10.1136/bmj.323.7323.1218. 